\title{
O Aperfeiçoamento Docente do Residente no Programa Residência Pedagógica - PRP na Escola Dom Malan nos Anos Iniciais do Ensino Fundamental
}

\author{
Magdala Isbele Alves da Cruz ; Aurelania Maria de Carvalho Menezes²; \\ Maria das Graças Bento Gonçalves e Oliveira ${ }^{3}$
}

\begin{abstract}
Resumo: Este trabalho tem como objetivo descrever as vivências do residente do Programa Residência Pedagógica - PRP, da Coordenação de Aperfeiçoamento de Pessoal de Nível Superior - CAPES, do Ministério da Educação do Brasil - MEC e parceria com a Faculdade de Ciências Humanas do Sertão Central. O PRP tem por principal objetivo, inserir os discentes em licenciaturas nas escolas de Educação Básica para o aperfeiçoamento das práticas docentes. Este artigo relata as experiências que colaboraram para a reflexão do residente sobre o fazer docente e suas dificuldades em sala de aula. O programa teve início com a fase de ambientação, que oportunizou conhecer o trabalho do gestor e demais funcionários da instituição, assim como suas atividades. Na fase de Imersão, os trabalhos aconteceram dentro da sala de aula, com a oportunidade de aperfeiçoar todo o fazer docente e em momentos de trabalhos coletivos envolvendo toda a instituição de ensino. Dos muitos problemas existentes em sala de aula, a leitura mereceu um olhar especial, pois constatou-se a necessidade de trabalhar mais leitura e principalmente incentivar as crianças a gostar de ler. Este trabalho tem abordagem qualitativa com ajuda de pesquisa bibliográfica. É uma pesquisa de campo, pois as vivências do PRP na Escola Dom Malan, foram descritas, analisadas e comentadas. Contou com teóricos como: Caiado (2019?), Fávero (1992), Ferreiro e Palácio (1987) e Piaget (2007).
\end{abstract}

Palavras-Chave: Ambientação. Imersão. Programa Residência Pedagógica. Prática docente. Vivências.

\section{The Resident's Teaching Improvement in the Pedagogical Residence Program - PRP in the Dom Malan School in the Early Years of Fundamental Education}

\begin{abstract}
This paper aims to describe the experiences of the resident of the Pedagogical Residency Program PRP, the Coordination for the Improvement of Higher Education Personnel - CAPES, the Ministry of Education of Brazil - MEC and partnership with the Faculty of Human Sciences of the Central Sertão. The main objective of the PRP is to insert students in undergraduate degrees in elementary schools to improve teaching practices. This article reports on the experiences that contributed to the resident's reflection on teaching practice and its difficulties in the classroom. The program began with the setting phase, which provided the opportunity to learn about the work of the manager and other employees of the institution, as well as their activities. In the Immersion phase, the work took place within the classroom, with the opportunity to improve all teaching and in moments of collective work involving the entire educational institution. Of the many problems that exist in the classroom, reading deserved a special look, as it became necessary to work more reading and especially encourage children to enjoy reading. This work has a qualitative approach with the help of bibliographic research. It is a field research, because the experiences of PRP at Dom Malan School were described, analyzed and commented. It counted on theorists such as: Caiado (2019), Fávero (1992), Blacksmith and Palace (1987) and Piaget (2007).
\end{abstract}

Keywords: Atmosphere. Immersion. Pedagogical Residence Program. Teaching practice. Experiences.

\footnotetext{
${ }^{1}$ Faculdade de Ciências Humanas do Sertão Central FACHUSC;

${ }^{2}$ Pedagoga. Faculdade de Ciências Humanas do Sertão Central FACHUSC. lelamenezesluiza@yahoo.com.br;

${ }^{3}$ Mestre, Universidade Católica de Pernambuco. professoragracabento@ hotmail.com.
} 


\section{Introdução}

Este trabalho tem a finalidade de relatar as experiências como residente do Programa Residência Pedagógica (PRP), pois este é voltado para a formação de profissionais na área da educação de forma que a construção do conhecimento acontece através da interação social e se desenvolve na prática.

O PRP é um programa da Coordenação de Aperfeiçoamento de Pessoal de Nível Superior - CAPES/MEC, com o objetivo de aperfeiçoar a prática do ensino docente. O programa teve início após a seleção realizada através do edital CAPES nº 06/2018, com as atividades distribuídas em um total de 440 horas, nas fases de ambientação e imersão. Em parceria com a Faculdade de Ciências Humanas do Sertão Central - FACHUSC, o PRP começou em agosto de 2018 e finalizará suas atividades em janeiro de 2020.

As licenciaturas em Pedagogia e Ciências Biológicas foram os cursos que participaram da seleção. Para o início do programa, os envolvidos passaram por capacitação, para chegar às escolas campo conhecendo os objetivos do programa. Grande parte dos selecionados foi encaminhada para a Escola Dom Malan na cidade de Salgueiro-PE, residentes de ambos os cursos.

O PRP contribui para a formação do graduando em licenciatura, favorecendo ao discente, unir teoria e prática, tendo em vista que este é o objetivo do licenciando em Pedagogia. O residentes são orientados por preceptores/professores da Educação Básica, facilitando a residência durante as atividades e percurso do programa.

O PRP foi dividido em duas fases: ambientação e imersão, respectivamente. A primeira fase começou levando o residente para o espaço escolar e conhecer os trabalhos exercidos pela gestão, secretaria escolar e documentos inerentes, tendo como principal foco, analisar o Projeto Político Pedagógico (PPP) e seus objetivos para o funcionamento da escola. Com o término da primeira fase, deu-se início fase seguinte, com as atividades direcionadas para a sala de aula, colocando em prática o fazer docente, contribuindo com a professora da sala nas atividades diárias e execução de projetos.

Este trabalho tem o objetivo de relatar as experiência da residência pedagógica, desde a observação na fase de Ambientação, conhecendo a estrutura física da escola campo, setor administrativo e funcionários. Na fase de Imersão, refletiu-se sobre as vivências em sala de 
aula, e a oportunidade de contribuir com a professora e alunos nas questões relacionadas ao ensino e aprendizagens.

Este artigo foi embasado nos trabalhos de teóricos como: Caiado (2019?), Fávero (1992), Ferreiro e Palácio (1987) e Piaget (2007).

\section{Programa Residência Pedagógica - PRP}

A CAPES criou o Programa Residência Pedagógica, com a proposta de trazer ao residente um aperfeiçoamento da prática docente, contribuindo para a Política Nacional de Formação de professores, provocando a reflexão sobre a escola atual. O PRP visa o fortalecimento entre a universidade e escola, permitindo.

Segundo o edital da Capes de 2018:

[...] A residência pedagógica consiste na imersão planejada e sistemática do aluno de licenciatura em ambiente escolar visando à vivência e experimentação de situações concretas do cotidiano escolar e da sala de aula que depois servirão de objeto de reflexão sobre a articulação entre teoria e prática. Durante e após a imersão o residente deve ser estimulado a refletir e avaliar sobre sua prática e relação com a profissionalização do docente escolar, para registro em relatório e contribuir para a avaliação de socialização de sua experiência como residente. (Edital CAPES, 06/2018).

O PRP é um programa do Governo Federal importante para o graduando de licenciaturas, pois permite refletir sobre o fazer do professor nos muitos aspectos, assim como as experiências em sala de aula, promovendo a imersão na escola de educação básica.

A seleção aconteceu através de uma carta motivacional solicitada por edital e proporcionou oportunidades aos licenciandos dos cursos de Pedagogia e Ciências Biológicas matriculados na Faculdade de Ciências Humanas do Sertão Central. O residente passou por formações e são monitorados e instruídos por um preceptor e este por um orientador. Após os encontros e as formações os residentes foram encaminhados para as respectivas escolas campo.

O PRP foi bem acolhido pela Escola Dom Malan na cidade de Salgueiro-PE, onde muitos residentes foram apresentados à escola pela equipe do programa. A escola acolheu os residentes e os mesmos foram convidados a conhecer o funcionamento e organização da instituição. A Escola Campo de residência Dom Malan, funciona com o ensino fundamental dos anos iniciais e finais, e conta atualmente com aproximadamente seiscentos alunos, 
distribuídos nos turnos manhã e tarde. Possui 59 (cinquenta e nove funcionários) entre professores, diretor, auxiliares de serviços gerais, auxiliares administrativos. Conta também com o trabalho dos estagiários para atender alunos com deficiências.

\section{Primeira fase do PRP: Ambientação}

No período de ambientação os residentes realizaram diversas atividades na instituição. Todos os departamentos foram contemplados com a presença de residentes e estes puderam conhecer um pouco do trabalho de cada um. A experiência de unir a teoria à prática proporcionou momentos de grandes aprendizados. Pode-se conhecer atividades com a direção, no setor administrativo, com professores em sala de aula, com regência e intervenção, na biblioteca, com os serviços gerais e na cozinha. Observou-se como eram as relações entre os funcionários da instituição, como trabalhavam em parceria, o ambiente geral e as instalações.

Durante a fase de Ambientação observou-se serviços inerentes à Secretaria Escolar como, renovação de matrículas, confecção de boletins, trabalhos diversos nos diários de classe, entrega de resultados, histórico escolar, documentação do Bolsa Família, reservas de matrículas, transferências e outros documentos. Mas o documento mais importante, tendo em vista a ansiedade em conhecer, foi o Projeto Político Pedagógico-PPP, pois é o documento que norteia uma instituição escolar.

A primeira fase foi de aprendizagens novas, pois as atividades da secretaria escolar eram desconhecidas pela maioria dos residentes do programa. Foi importante conhecer o trabalho de uma gestão democrática e o ambiente harmonioso que demonstra viver a escola Dom Malan.

\section{Segunda Fase do PRP: Imersão, prática docente e intervenção}

O Programa Residência Pedagógica proporcionou ao graduando/residente maior conhecimento a respeito do fazer docente, pois esta fase favoreceu a união entre teoria e prática. Para Fávero (1992): 
competências e habilidades através da supervisão de professores atuantes, tendo a relação direta da teoria com a prática cotidiana. Pois unir teoria e prática é um grande desafio com o qual o educando de um curso de licenciatura tem de lidar. E, se esse problema não for resolvido ou pelo menos suavizado durante a vida acadêmica do estudante, essa dificuldade se refletirá no seu trabalho como professor. Não é apenas frequentando um curso de graduação que uma pessoa se torna profissional. É, principalmente, envolvendo-se intensamente como construtor de umas práxis que o profissional se forma (FÁVERO, 1992).

A fase de Imersão e de intervenção em sala de aula proporcionou uma efetiva comunhão e troca de conhecimentos entre o docente e o residente. Essa fase aconteceu numa turma do $3^{\circ}$ ano do Ensino Fundamental, na Escola Dom Malan. Durante a Imersão foi constatada a necessidade de um trabalho aprofundado de leitura e por tal problema, elaborou-se um projeto de intervenção para incentivar nas crianças o gosto pela leitura. Sabe-se que uma boa leitura é fundamental para o processo de ensino e aprendizagem. Através da leitura a criança poderá compreender o mundo, por isso é importante que ela seja trabalhada diariamente em sala e o professor deve estar atento para aplicar metodologias que consigam resultados positivos, com o cuidado de atender as especificidades de uma sala de aula e assim, desenvolver muitas habilidades, que serão importantes para as crianças.

\section{Dificuldades com a leitura e o incentivo da escola e da família para seu desenvolvimento}

Nos dias atuais, é comum encontrar professores que travam verdadeiras batalhas com as dificuldades com a leitura, pois sabe-se que tais problemas comprometem o ensino e a aprendizagem.

As dificuldades com a leitura não pertencem somente às escolas públicas. Conforme Caiado (2019?), as escolas públicas apresentam maior índice em relação a dificuldade com a leitura, mas também é uma realidade nas instituições de ensino privado.

As dificuldades apresentadas na leitura estão intensamente ligadas ao desenvolvimento da habilidade escrita. É importante aplicar estratégias para facilitar o desenvolvimento no processo de leitura, principalmente tornando o ato de ler prazeroso e menos cansativa.

Para Ferreiro e Palácio (1987), o ato de ler é beneficiado de uma variedade de opções, “o leitor não responde simplesmente aos estímulos do meio, e sim, desenvolve estratégias para trabalhar com texto de tal maneira que seja possível compreendê-lo". O hábito da leitura é de suma importância porque é através da leitura que se abre novos horizontes onde tornamos

938 Id on Line Rev. Mult. Psic. V.13, N. 48 p. 934-943, Dezembro/2019 - ISSN 1981-1179 Edição eletrônica em http://idonline.emnuvens.com.br/id 
capazes de aprofundar os conhecimentos sobre o mundo e torna - se um cidadão crítico e conhecedor dos seus direitos.

A família é peça chave no processo de desenvolvimento da leitura, principalmente por se tratar de uma etapa importante na vida da criança, deve incentivar desde pequeno, lendo histórias para ir despertando o gosto pela leitura.

Na escola campo de residência existe uma boa relação entre pais e escola, pois a maioria dos pais é participativa, colaborando com a vida educacional de seus filhos. É imprescindível que esta parceria aconteça, tendo em vista o desenvolvimento do educando em casa e na escola.

Piaget (2007, p.50) ressalta a importância da ligação entre pais e professores, pois este intercâmbio acaba resultando em ajuda recíproca e, frequentemente, em aperfeiçoamento real dos métodos. Ao aproximar a escola da vida ou das preocupações profissionais dos pais, e ao proporcionar, reciprocamente, aos pais um interesse pelas coisas da escola chega-se até mesmo a uma divisão de responsabilidades. Sendo assim, percebe-se que a iniciativa de melhorias na educação e aprendizagem do aluno não pode partir somente da escola, mas também da família que passa grande parte do tempo com a criança. A educação deve ser trabalhada em parceria, família e escola.

\section{Metodologia}

Este trabalho apresenta abordagem qualitativa e foi desenvolvido com ajuda de uma pesquisa bibliográfica. É uma pesquisa de campo, pois as vivências do Programa Residência Pedagógica na Escola Dom Malan, foram descritas, analisadas e comentadas.

\section{Resultados e Discussão}

O Programa Residência Pedagógica (PRP) da CAPES, proporcionou dois mini cursos para os residentes/graduandos, preceptores, orientadores e demais envolvidos com o programa. O primeiro foi de Leitura e Produção textual e o segundo mini curso foi de Oratória. Cada um com a duração de 8 horas. Os mini cursos ajudaram os residentes a desenvolverem suas produções tanto para o PRP como para a faculdade. 
Figura 1: Palestrante Doutoranda Socorro Cordeiro sobre Leitura e Produção Textual

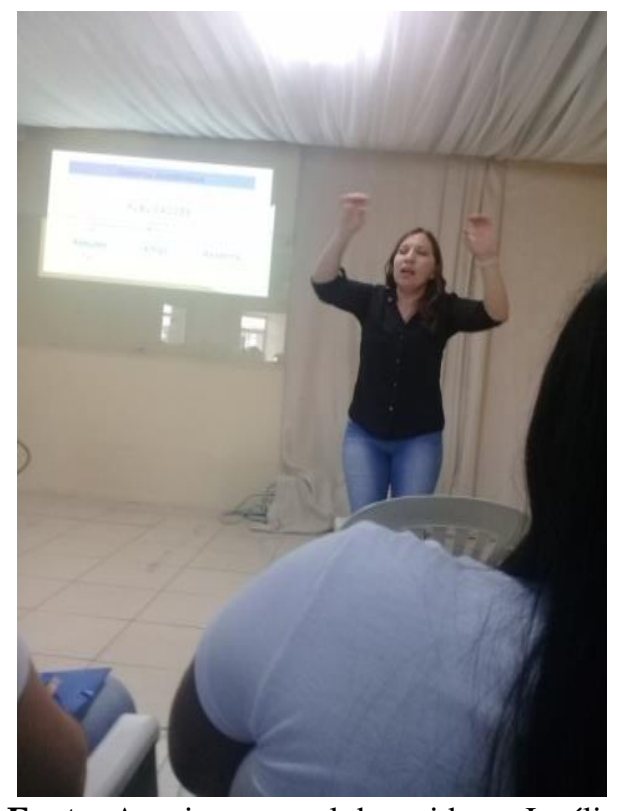

Fonte: Arquivo pessoal da residente Josélia

Figura 2: Palestrante Dr. Tiago, sobre Oratória

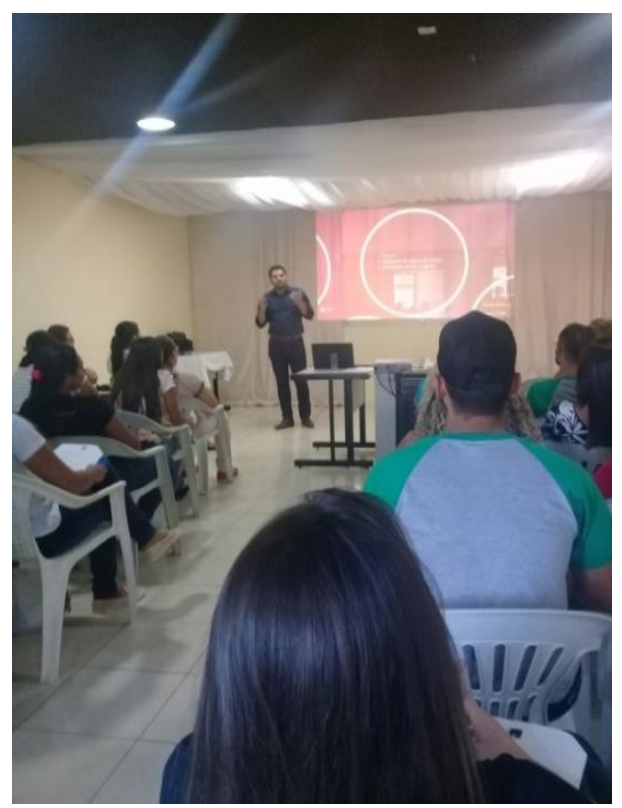

Fonte: Arquivo pessoal da residente Josélia

A primeira fase, denominada de Ambientação, inseriu o graduando/residente dentro de uma escola de Educação Básica para conhecer seu funcionamento. Pode-se conhecer o setor administrativo e seus muitos documentos. Salientando que o Projeto Político Pedagógico (PPP) 
é um dos principais documentos de uma escola. $\mathrm{O}$ trabalho realizado pela equipe gestora é considerado democrático em todos os aspectos.

Como complemento e término da primeira fase foi solicitada uma atividade de produção pelo programa, um Resumo expandido, que foi orientado pelo preceptor. Outros trabalhos foram solicitados pela escola campo, como projetos e atividades avaliativas ou recreativas para a sala de aula.

Com o início da segunda fase do programa, a Imersão, aconteceu o I Congresso de Ensino, Pesquisa e Extensão da Faculdade de Ciências Humanas do Sertão Central, onde os residentes de Pedagogia e Ciências Biológicas, com o PRP e o PIBID - Programa Institucional de Bolsa de Iniciação à Docência, onde tiveram a oportunidade de apresentar os Resumos Expandidos em forma de Banner, contendo relatos de atividades programadas pelo PRP e Escola Campo.

A segunda fase do PRP é denominada de Imersão e proporcionou colocar em prática a teoria das aulas da faculdade, proporcionado uma prática efetiva. Esta etapa foi vivenciada com muitas atividades e projetos que contribuíram para a transformação de muitas realidades.

$\mathrm{Na}$ sala de aula, muitas atividades foram desenvolvidas para trabalhar as dificuldades de aprendizagens. Foram realizados projetos para a sala de aula e outros para toda a escola. Muitas datas comemorativas foram celebradas estudando seu percurso histórico.

Um dos projetos que a escola vivenciou foi o de leitura, onde os alunos eram convidados a ler e incentivar os colegas. Segue abaixo figuras 3 e 4 sobre as atividades de leitura realizada na sala de aula.

O Programa Residência Pedagógica - PRP possibilitou ao residente/graduando, conhecer o funcionamento de uma instituição escolar, da gestão, passando por secretaria, cozinha, serviços gerais até à sala de aula, esta, sendo o alvo principal do PRP. 
Figura n⿳0 03 - Momento de leitura da fase de imersão/intervenção

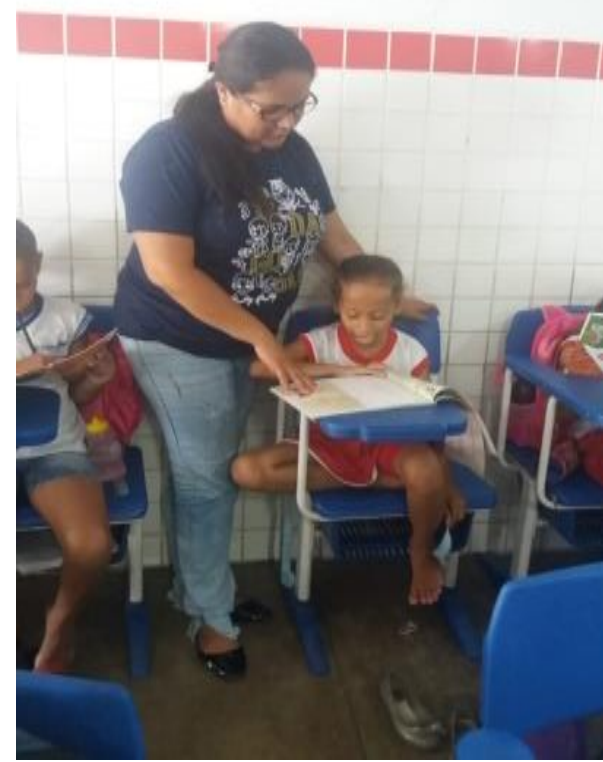

Fonte: Arquivo pessoal

Foto $\mathbf{n}^{0} 04$ - Momento de atendimento individual de leitura da fase de imersão

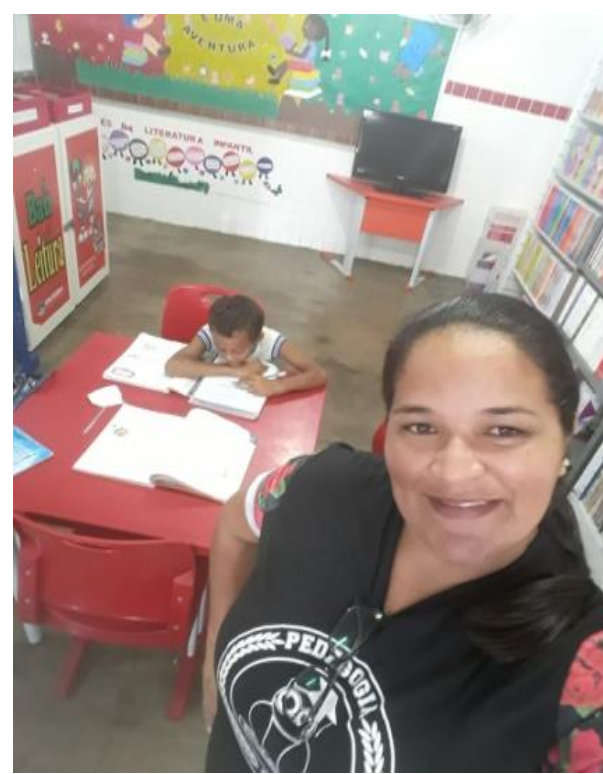

Fonte: Arquivo pessoal 


\section{Conclusões}

O programa abre portas para o aperfeiçoamento da prática docente. As experiências adquiridas com o Programa de Residência Pedagógica - PRP proporcionaram diversas aprendizagens que serão usadas quando necessárias na futura atuação docente.

Percebeu-se que um bom trabalho de uma gestão educacional é essencial para o funcionamento escolar como também a importância do docente cada vez mais e em busca de novos saberes.

\section{Referências}

BRASIL. Edital CAPES no 06/2018. Programa Residência Pedagógica. Disponível em https://www.capes.gov.br/images/stories/download/editais/01032018-Edital-6-2018$\underline{\text { Residencia-pedagogica.pdf }}$

CAIADO, Elen Campos. Como orientar os alunos com dificuldades na leitura. (2019?) Disponível em https://educador.brasilescola.uol.com.br/sugestoes-pais-professores/comoorientar-os-alunos-com-dificuldades-na-leitura.htm. Acesso em 20/08/2019.

FÁVERO, Leonor Lopes. A Dissertação. São Paulo: USP/VITAE, 1992. 104 p.

FERREIRO, Emilia; PALACIO, Margarita Gomes. Os processos de leitura e escrita: novas perspectivas. Traduzido por: Luiza Maria Silveira. 3 ed. Porto Alegre: Artes Médicas, 1987.

PIAGET, Jean. Para onde vai a educação?. Rio de Janeiro: José Olímpio, 2007.

\section{Como citar este artigo (Formato ABNT):}

CRUZ, Magdala Isbele Alves da; MENEZES, Aurelania Maria de Carvalho; OLIVEIRA, Maria das Graças Bento Gonçalves e. O Aperfeiçoamento Docente do Residente no Programa Residência Pedagógica - PRP na Escola Dom Malan nos Anos Iniciais do Ensino Fundamental. Id on Line Rev.Mult. Psic., Dezembro/2019, vol.13, n.48, p. 934-943 . ISSN: 1981-1179.

Recebido: $02 / 12 / 2019$

Aceito: 05/12/2019 